\title{
Efeitos da adoção do Programa de Núcleos de Apoio à Gestão \\ da Inovação nas práticas de controle gerencial
}

\section{lago França Lopes, Vanderlei dos Santos, llse Maria Beuren}

\author{
Universidade Federal de Santa Catarina (UFSC) \\ Universidade do Estado de Santa Catarina (UDESC) \\ Universidade Federal de Santa Catarina (UFSC)
}

O estudo objetiva identificar os reflexos da adoção do Programa de Núcleos de Apoio à Gestão da Inovação (NAGI) nas práticas de controle gerencial. Pesquisa descritiva foi realizada a partir de um levantamento, tendo como amostra 12 empresas brasileiras respondentes do questionário que aderiram ao Programa. Os dados foram analisados com aplicação de estatística descritiva e entropia informacional. Os resultados mostram que as empresas passaram a utilizar com maior intensidade os artefatos investigados, destacando-se a avaliação de desempenho, o planejamento estratégico, a margem de contribuição, simulaçôes e o orçamento. Constatou-se que as empresas passaram a utilizar as demonstraçóes contábeis na tomada de decisão e o planejamento estratégico tornou-se uma prática de controle gerencial adotada de forma homogênea. Os níveis de mudanças ocorridos nas práticas de controle gerencial com a introdução de inovaçóes nas organizaçóes coadunam com os observados por Sulaiman e Mitchel (2005), em especial nas práticas de planejamento, controle e custeio.

Palavras-chave: Programa de Núcleos de Apoio à Gestão da Inovação, práticas de controle gerencial, controles operacionais, métodos de custeio, instrumentos gerenciais.

\section{Impact of adopting the Innovation Management Support Center Program on management control practices}

The study aims to identify the impact of adopting the program for Centers of Support for Innovation Management (Programa de Núcleos de Apoio à Gestáo da Inovação - NAGI) on management control. This descriptive research carried out a survey, having as sample 12 Brazilian companies that joined the program. Data were analyzed using descriptive statistics and information entropy. Results showed that companies started using the researched systems more intensively, especially performance evaluation, strategic planning, contribution margin, simulations and budget. It was found that the companies started to use financial statements for decision-making, and strategic planning became a standard management control practice. The changes in management control practices after introducing innovation systems in the organizations were consistent with those observed by Sulaiman and Mitchell (2005), especially in planning, control and financial practices.

Keywords: Centers of Support for Innovation Management, management control practices, operational control, costing methods, management tools. 


\section{Efectos de la adopción del Programa de Núcleos de Apoyo a la Gestión de la Innovación en las prácticas de control de gestión}

El estudio tiene como objetivo identificar los efectos causador al adoptar el Programa de Núcleos de Apoyo para la Gestión de Innovación (Programa de Núcleos de Apoio à Gestão da Inovação - NAGI) en las prácticas de control de gestión. El estudio descriptivo se realizó a partir de una encuesta, con una muestra de 12 empresas brasileñas adheridas al programa. Los datos fueron analizados con estadística descriptiva y entropía de la información. Los resultados muestran que las empresas comenzaron a utilizar más los sistemas investigados, destacándose la evaluación del desempeño, la planificación estratégica, el margen de contribución, simulaciones y presupuesto. Se encontró que las empresas comenzaron a utilizar los estados financieros para tomar decisiones; y la planificación estratégica se ha convertido en una práctica de control de gestión adoptada de forma homogénea. Los cambios ocurridos en el control de gestión después de introducir estas innovaciones en las organizaciones son consistentes con los cambios observados por Sulaiman y Mitchell (2005), especialmente en las prácticas de planificación, control y costeo.

Palabras clave: Programa de Centros de Apoyo a la Gestión de la Innovación, prácticas de control de gestión, controles operacionales, métodos de costeo, herramientas de gestión.

\section{Introduçáo}

O Programa de Núcleos de Apoio à Gestão da Inovação (NAGI) foi criado a partir de uma iniciativa governamental, como forma de intensificar os processos de inovação nas empresas estabelecidas no Brasil. O Programa conta com consultores para dar suporte na condução e construçáo de processos inovadores nas empresas, por meio de metodologias aplicáveis ao contexto de cada organização. Sua finalidade é transferir conhecimentos e metodologias de inovação às empresas por meio de atendimento individualizado.

O incentivo à inovação surge, no Brasil, como uma articulação que envolve o governo, empresas e universidades, em uma hélice tríplice (Loures \& Bicalho, 2014), para assegurar o desempenho da inovação e a performance organizacional (Tsai, 2004; Dunk, 2011; Camisón \& Villar-Lopez, 2014), tendo em vista que o processo inovativo é oneroso e exige da organizaçáo preparo para a receptividade da mudança.

Alinhado a esta proposta, vale ressaltar que as práticas de controle gerencial têm o propósito de auxiliar no alcance dos objetivos organizacionais, pois se revestem de relevância no suporte ao processo decisório e para auxiliar os gestores na otimização dos recursos. Em essência, as práticas de controle gerencial buscam equilibrar o controle e a flexibilidade dos processos internos e externos da organizaçáo (Dias Filho \& Nakagawa, 2001).

Para Simons (1990), os controles gerenciais são parte de um sistema social dinâmico, que exerce influência positiva sobre o processo de gestão da inovação. Mat, Smith e Djajadikerta (2010) constataram que as mudanças das práticas de controle gerencial estáo positivamente relacionadas com o avanço da tecnologia e com as mudanças de estratégias organizacionais. $\mathrm{Li}$ (2014) destaca que as pressóes vindas do governo, de clientes e da concorrência exercem impacto positivo nas práticas de inovação, e que as práticas de inovação têm efeito positivo sobre o desempenho da empresa.

Bisbe e Otley (2004) e Oyadomari, Aguiar, Chen e Dultra-De-Lima (2013a) observaram estabilidade nas práticas de controle gerencial. Contudo, o cenário se contrapóe às supostas mudanças necessárias para a 
harmonização entre práticas de controle gerencial e sistemas de inovação. Neste sentido, é relevante a discussão relativa a necessidade de inovação e de controle com vistas em assegurar a continuidade dos negócios empresariais.

Com base no exposto, elaborou-se a seguinte pergunta de pesquisa: Quais os reflexos da adoção do Programa de Núcleos de Apoio à Gestão da Inovação (NAGI) nas práticas de controle gerencial em empresas? Assim, o objetivo geral do estudo é identificar os reflexos da adoção do Programa de Núcleos de Apoio à Gestão da Inovação (NAGI) nas práticas de controle gerencial. Como objetivos específicos buscam-se: (i) identificar as iniciativas de inovação promovidas nas empresas com o Programa NAGI; e (ii) averiguar as práticas de controle gerencial utilizadas pelas empresas para dar suporte ao Programa NAGI.

Espera-se que os resultados dessa pesquisa possam contribuir com os profissionais da área contábil responsáveis pelo suporte à tomada de decisóes e adequação das práticas de controle gerencial frente à adoção de programas de gestão da inovação. $\mathrm{O}$ estudo busca amplificar a compreensáo sobre os reflexos da inovação nas práticas de controle gerencial. Nisiyama e Oyadomari (2012, p. 108) mencionam que «apesar dos temas inovação e controles estarem presentes em muitos estudos, a literatura nacional carece de pesquisas que analisem as relaçóes entre os controles gerenciais e o processo de gestáo da inovação».

Outro cenário que deve ser observado, que também justifica a realização deste estudo, é o crescente investimento do governo em programas de inovaçáo para auxiliar as organizaçóes no desenvolvimento de processos inovadores. Esse aspecto consiste em compreender o comportamento destas iniciativas governamentais em relação às práticas de controle gerencial.
Tal compreensão implica em benefícios diretos e indiretos às organizaçóes, inclusive sob a perspectiva econômica, como a diminuição de custos decorrentes do processo de Pesquisa, Desenvolvimento e Inovação (PD\&I).

\section{Inovação e controle gerencial}

Inovação é um elemento chave para o desenvolvimento econômico da empresa, Segundo Davila, Epstein e Shelton (2007, p. 21), «não é apenas a oportunidade de crescer e sobreviver, mas também, de influenciar decisivamente os rumos da indústria em que se insere». A inovação tem se apresentado como influenciadora das açóes organizacionais no cumprimento das metas pré-estabelecidas, criando um direcionamento para equilibrar mudanças de práticas gerenciais e necessidades organizacionais (Bisbe \& Otley, 2004).

Drucker (1999) expóem que a inovação «é o esforço para criar mudanças objetivamente focadas no potencial econômico e social de um empreendimento". Essa definição se situa como um acerto nesta pesquisa, por conceber a inovaçáo como um agente de mudança organizacional. Dentro desse processo, as práticas de controle gerencial são fundamentais, uma vez que contribuem para a implementação e controle dos processos relacionados à gestáo da inovação (Frezatti, Bido, Cruz \& Machado, 2015).

No ambiente científico, as práticas de controle gerencial e inovação têm chamado atenção de pesquisadores. Entender como a organização usa as práticas de controle gerencial no suporte à gestão da inovação tem emergido como uma importante questáo de pesquisa (Bisbe \& Otley, 2004). Simons (1990) criou um modelo para mostrar como o gerenciamento das práticas de controle gerencial pode contribuir para o desenvolvimento de estratégicas competitivas. $\mathrm{O}$ autor resaltou 
a importância de formas, estratégias e processos, criando um cenário propício à discussão de uma linguagem adequada para comunicar e desenvolver os conceitos necessários aos fenômenos organizacionais complexos.

Davila (2000) fez uso da abordagem contingencial para compreender como as empresas adaptam suas práticas de controle gerencial no desenvolvimento de novos produtos. Ele afirma que «as práticas de controle gerencial e o desenvolvimento de novos produtos são vistos como fontes de informação usadas para fechar a lacuna entre as informaçóes necessárias para executar uma tarefa e a quantidade de informação já possuída» (Davila, 2000, p. 386). Bisbe e Otley (2004) aplicaram o modelo de Simons e observaram que quanto maior o uso interativo de práticas de controle gerencial por CEO's por meio da inovação, melhor o desempenho empresarial, e quanto maior o uso interativo das práticas de controle gerencial maior será o efeito no desempenho da inovação de produtos.

$\mathrm{Na}$ literatura nacional, entre os estudos que analisam as práticas de controle gerencial associadas à inovação, semelhante ao ora proposto, destacam-se os de Nisiyama e Oyadomari (2012), Oyadomari et al. (2013a), Oyadomari, Mendonça Neto e Cardoso (2013b) e Oyadomari, Cardoso, Mendonça Neto e Aguiar (2013c), Frezatti et al. (2015). Nisiyama e Yadomari (2012) identificaram contribuições dos estudos empíricos internacionais para o desenvolvimento de pesquisas brasileiras na análise da relação entre Sistema de Controle Gerencial (SCG) e inovação, e constataram que nesses estudos tem predominado o uso do modelo de controle de Simons.

Oyadomari et al. (2013a) verificaram como os profissionais de controladoria adquirem informaçóes e as transformam em de práticas de controle gerencial. Oyadomari et al. (2013b) buscaram compreender os fatores indutores de inovação e de manutenção das práticas de controle gerencial e constataram a existência de correlação com quatro fatores indutores da inovação. Oyadomari et al. (2013c) mapearam pesquisas internacionais sobre práticas de controle gerencial com o propósito de gerar conhecimento. Observaram que é relevante o desenvolvimento de pesquisas que abordam a inovação e práticas de controle gerencial em ambientes organizacionais específicos, com o intuito de analisar o estágio de adoçáo das práticas de controle gerencial em cada empresa. Frezatti et al. (2015) investigaram o papel dos perfis estratégicos e instrumentos do controle gerencial no processo de inovação das organizaçóes e encontram uma associação entre os tipos de inovação (incremental e radical) e os artefatos de controle gerencial por eles defendidos como os mais adequados para a implementação da gestão da inovação em uma empresa.

As pesquisas apresentadas contribuem para o entendimento do status quo da pesquisa sobre práticas de controle gerencial e inovaçáo em termos internacionais e nacionais. No entanto, neste estudo as práticas de controle gerencial e a inovação são estudadas sob a ótica da mudança organizacional, focalizando a adequação de práticas de controle gerencial com a adoção de incentivos ao desenvolvimento da inovação empresarial. Esse foco está alinhado com o estudo de Sulaiman e Mitchell (2005), que analisou as empresas listadas na Bolsa de Valores da Malásia considerando um período de cinco anos. $\mathrm{O}$ estudo evidenciou que as empresas realizaram em média 1,9 mudanças na Contabilidade Gerencial. No entanto, os resultados apontaram dificuldades e resistências na implementação das mudanças, escopo que incentivou a realização desta pesquisa. Sulaiman e Mitchell (2005) apresentaram tipologias de mudança nas práticas de controle gerencial em empresas, destacas no Quadro 1. 
Quadiro 1. Tipologias de mudanças em práticas de controle gerencial

\begin{tabular}{|l|l|}
\hline \multicolumn{1}{|c|}{ Tipologias } & \multicolumn{1}{c|}{ Mudanças em práticas de controle gerencial } \\
\hline Adição & $\begin{array}{l}\text { Introdução de novas técnicas como extensão do sistema de contabilidade gerencial, por exemplo, custo da } \\
\text { qualidade, indicadores náo monetários. }\end{array}$ \\
\hline Reposição & $\begin{array}{l}\text { Introdução de novas técnicas como reposição de partes de técnicas já existentes, por exemplo, orçamento } \\
\text { flexível com orçamento fixo, custeio por atividades dentro do sistema de custos. }\end{array}$ \\
\hline $\begin{array}{l}\text { Modificação } \\
\text { do relatório }\end{array}$ & $\begin{array}{l}\text { Modificação da informação relatada, por exemplo, alteração de análise mensal para semanal das variações } \\
\text { orçamentárias, ou forma de apresentação numérica para gráfica. }\end{array}$ \\
\hline $\begin{array}{l}\text { Modificação } \\
\text { operacional }\end{array}$ & $\begin{array}{l}\text { Modificação de uma operação técnica do sistema de contabilidade gerencial, por exemplo, o uso de taxa } \\
\text { predeterminada em oposiçáo a uma taxa real, ou o uso de análise de regressáo em vez de análise separando } \\
\text { custos fixos e variáveis. }\end{array}$ \\
\hline Redução & $\begin{array}{l}\text { Remoção de uma técnica de contabilidade gerencial sem reposição por outra, por exemplo, abandono do } \\
\text { orçamento ou da análise do ponto de equilíbrio. }\end{array}$ \\
\hline
\end{tabular}

Fonte: Adaptado de Sulaiman e Mitchell (2005) e Oyadomari et al. (2013a).

Frezatti et al. (2015) expóem que as práticas de controle gerencial permitem a implantação e controle dos processos de inovação na empresa, pois constituem um conjunto de elementos relevantes para a formalização das estratégias e, portanto, para organizar o processo de inovação. As práticas de controle gerencial compreendem «sistemas de medição que são usados para concentrar atenção constante na mutação de informação que os gestores de nível superior consideram ser de nível estratégico» (Bisbe \& Otley, 2004, p. 711).

\section{Planejamento Estratégico, Balanced Scorecard, Orça-} mento, Rolling Forescast e Controle Orçamentário foram apontados por Frezatti et al. (2015) como instrumentos que permitem a implementaçáo e controle de processos de inovação. "Críticas frequentes deste conjunto de instrumentos referem-se à maneira pela qual eles podem implementar decisóes e a maneira pela qual eles são gerenciados» (Frezatti et al., 2015, p. 131). Oyadomari et al. (2013a) abordam a mudança nas práticas de controle gerencial enfatizando as tipologias preconizadas por Sulaiman e Mitchell (2005), quanto à adição, reposição, modificação de relatório, modificação operacional e redução de práticas de controle gerencial.

Em âmbito internacional, as práticas de controle de gestão mais usuais, identificadas em estudos que averiguaram o reflexo da inovação, são: Orçamento, Desempenho Corporativo, Métodos de Custeio e Planejamento Estratégico (Simons, 1990); Sistemas de Gerenciamento de Projetos, Orçamento, Métodos de Custeio e Avaliação de Desempenho (Davila, 2000); Orçamento, Balanced Scorecard e Sistemas de Gerenciamento de Projetos (Bisbe \& Otley, 2004).

Neste estudo investigam-se as seguintes práticas de controle gerencial: controles operacionais (Controle de caixa, Controle de contas a pagar, Controle de contas a receber, Controle de estoques, Controle de vendas, Controle de custos e despesas, Controle de resultados, Demonstraçóes contábeis); métodos de custeio (Custeio por absorção, Custeio variável, Custeio padrão, Custeio baseado em atividades, Custeio meta); outras práticas gerenciais (Planejamento estratégico, Planejamento tributário, Ponto de equilíbrio, Orçamento, Avaliação de desempenho, Simulaçóes 
e Margem de contribuição). A opção pela inclusão dos controles operacionais e exclusão de artefatos como Balanced Scorecard, Rolling Forescast, sistemas de gerenciamento de projetos, decorre das características da amostra, já que as empresas participantes do NAGI são, na maioria, de pequeno porte.

\section{Programa de Núcleos de Apoio à Gestáo da Inovaçáo (NAGI)}

Os Núcleos de Apoio à Gestão da Inovação são projetos viabilizados em vários Estados do País, com aporte de recursos do Governo Federal (FINEP), alinhados ao Plano Brasil Maior, «que tem como meta elevar o dispêndio empresarial em PD\&I em 0,90\% do Produto Interno Bruto (PIB) (meta compartilhada com a Estratégia Nacional de Ciência e Tecnologia e Inovação ENCTI)» (Lopes \& Beuren, 2014, p. 02). Conhecido como programa NAGI, esse tem por objetivo transferir conhecimentos e metodologias aplicáveis à gestão da inovação nas empresas participantes do Programa.

Com este incentivo a indústria conta com atendimentos individualizados e tem à sua disposição consultores capacitados e metodologias aplicáveis voltadas especialmente ao contexto de cada empresa. A finalidade principal do Programa é promover o desenvolvimento econômico e social por meio do incentivo à Ciência, Tecnologia e Inovação nas empresas, baseado na seguinte metodologia: i) identificar novas oportunidades de negócios; ii) identificar e aproximar linhas de fomento público ou privado para desenvolver inovaçóes; e iii) implantar um processo de gestão da inovação nas empresas, para que a busca por novas oportunidades seja sistemática (Couto \& Turetta, 2013; SENAI/PR, 2014).

A estrutura dos núcleos visa o trabalho conjunto, com compartilhamento de experiências entre a equipe de consultores e pesquisadores de desenvolvimento tecnológico industrial e a equipe da empresa. $\mathrm{O}$ desenvolvimento desse processo acontece em seis etapas: a) diagnóstico do grau de maturidade quanto à gestão da inovação na empresa; b) análise do ambiente competitivo da empresa; c) nivelamento de conceitos inovadores; d) workshop de capacitação e geração de ideias e oportunidades de negócios; e) plano de açáo para as oportunidades e plano de gestão da inovação; e f) pré-projeto para a captação de recursos em agências de fomento e instituiçóes financeiras (SENAI/ PR, 2014).

Segundo Couto e Turetta (2013), após a realização das etapas evidenciadas, são geradas três soluçôes, que servirão de termo de referência para o empresário começar a inovar: plano de oportunidades em inovaçáo (plano de ação para guiar o empresário na implantação de novas oportunidades); plano de gestáo da inovaçáo (práticas de gestão a serem implantadas na empresa); e termo de abertura de projetos (tópicos essenciais para nortear o projeto na identificaçáo e seleção de uma linha ou edital de fomento).

No estado do Paraná, por exemplo, o Programa tem como meta desenvolver, capacitar e aplicar uma metodologia de assessoramento empresarial para a elaboração de planos de gestão da inovação para 80 organizaçóes, visando fortalecer sua competitividade e sustentabilidade. O pressuposto é que a gestão da inovação permite que as empresas tornem-se mais proativas no que diz respeito à busca por novas oportunidades de negócios e aperfeiçoamento constante de seus processos e produtos (Couto \& Turetta, 2013). Além disso, é esperado que as empresas participantes possam identificar e executar melhorias em seu ambiente de trabalho, reduzindo custos, aumentando a produtividade e identificando meios de captar maior valor na comercialização de seus produtos. 


\section{Procedimentos metodológicos}

Este estudo, quanto à natureza, é de caráter descritivo, pois visa descrever os reflexos da adoção do Programa NAGI nas práticas de controle gerencial. O procedimento adotado para a coleta de dados consiste da técnica de levantamento (survey), que permitiu a análise ex post facto. A coleta de dados foi realizada via e-mail, por meio do envio de um questionário de elaboração própria e sustentado pela literatura exposta no referencial teórico.

A população do estudo compóe-se das empresas que adotaram o Programa NAGI, no período de 2012 a 2014. O Programa surgiu como uma interface para preencher a lacuna existente entre a capacidade de inovação das empresas e o custo desse processo. No site do Programa NAGI estão identificaram-se 95 empresas localizadas no estado do Paraná.

Os sujeitos respondentes do questionário selecionados são os gestores do departamento de Pesquisa, Desenvolvimento e Inovação de cada empresa. O contato ocorreu via e-mail dos gestores, para o qual foi enviada uma carta de apresentaçáo da proposta do estudo com o link do instrumento da pesquisa. Ao todo, foram respondidos 12 questionários, o que constitui uma amostra por acessibilidade.

O questionário foi dividido em cinco partes. A primeira e segunda para obter informaçóes sobre o respondente e a empresa, respectivamente. A terceira para identificar o grau de utilizaçáo das práticas de contabilidade gerencial das empresas antes e após a implementação do Programa NAGI. As práticas de contabilidade gerencial foram segregadas em controles operacionais, métodos de custeio e outros instrumentos/práticas gerenciais.
Foram expostos oito controles operacionais (controle de caixa, controle de contas a pagar, controle de contas a receber, controle de estoques, controle de vendas, controle de custos e despesas, controle de resultados e demonstrações contábeis); cinco métodos de custeio (custeio por absorção, custeio variável, custeio padrão, custeio baseado em atividades e custeio meta); e sete outras práticas gerenciais (planejamento estratégico, planejamento tributário, ponto de equilíbrio, orçamento, avaliação de desempenho, simulações e margem de contribuição). Neste bloco de questôes, utilizou-se escala Likert de cinco pontos, sendo $0=$ não utiliza, 1=utiliza pouco, 2=utiliza razoavelmente, $3=$ utiliza medianamente e $4=$ utiliza muito.

Para melhor compreensão por parte dos gestores, foram expostos os conceitos e a denominação das práticas gerenciais nas categorias de métodos de custeio e outros instrumentos gerenciais. Os controles operacionais foram extraídos e adaptados das pesquisas de Lima (2007) e Lima e Imoniana (2008). Os métodos de custeio foram retirados dos estudos de Soutes (2006). E os outros instrumentos/práticas gerenciais foram extraídos dos estudos de Soutes (2006) e Panucci Filho e Almeida (2011).

O quarto bloco compreendeu as iniciativas de inovação das empresas utilizando o programa NAGI. Para tanto, analisaram-se quatro variáveis: oportunidades de negócios (Schumpeter, 1988), gestão da inovação (Martins, Alves \& Plonski, 2013), captação de inovação (Garcia, 2014), desenvolvimento e inovação (Tavares, Aquino \& Paiva, 2014). As assertivas constaram em escala Likert, sendo $1=$ discordo totalmente e $5=$ concordo totalmente.

O quinto e último bloco contemplou a tipologia de mudanças em práticas de controle gerencial, conforme proposto por Sulaiman e Mitchell (2005) - adição, 
reposição, modificação do relatório, modificação operacional e redução - e por Oyadomari et al. (2013a) na categoria estabilidade. Neste bloco, as questóes também foram apresentadas em escala Likert, sendo $1=$ discordo totalmente e $5=$ concordo totalmente.

$\mathrm{Na}$ análise dos dados, inicialmente apresentaram-se iniciativas de inovação promovidas pelo Programa NAGI, nas categorias de oportunidades de negócios, gestão da inovação, captação de fomento e desenvolvimento e inovaçáo. Para tanto, utilizou-se de estatística descritiva (média, moda, mínimo, máximo) e de entropia informacional para analisar as respostas obtidas. Em seguida, analisaram-se as práticas de controle gerencial utilizadas antes e após a adoção do Programa por meio de estatística descritiva e entropia informacional. Por fim, quantificaram-se as questóes no que diz respeito à tipologia de mudanças em práticas de controle gerencial.

\section{Descrição e análise dos resultados}

Os dados demográficos dos respondentes da pesquisa revelam que nove são do gênero masculino e três feminino. Desses, sete possuem acima de 40 anos e cinco se encontram na faixa entre 32 a 38 anos. A idade mínima encontrada foi de 32 anos e a máxima de 66 anos. Em relação à escolaridade, com exceção de um respondente, onze possuem graduação, sendo que oito já concluíram um curso de especialização e outro gestor possui mestrado. As funçóes exercidas pelos respondentes são de presidente (5), diretor (5) e gerente (2). A maioria exerce a função entre 01 a 10 anos, sendo que seis respondentes exercem entre 01 a 05 anos e quatro entre 06 a 10 anos. Um dos respondentes exerce a função de diretor há 24 anos.

Em relação às empresas, oito são tributadas pelo Simples Nacional, duas pelo Lucro Presumido e duas pelo Lucro Real. $\mathrm{Na}$ amostra, seis são indústrias e as demais são prestadoras de serviços, sendo duas na área de software. Quanto ao porte das empresas, quatro são microempresas (faturamento igual ou inferior a R\$ 240 mil), cinco são empresas de pequeno porte (faturamento superior a R\$240 mil e inferior ou igual a $\mathrm{R} \$ 2,4$ milhóes) e três são pequenas empresas (faturamento superior a $\mathrm{R}$ \$ 2,4 milhóes e inferior ou igual a R \$10,5 milhóes) conforme classificação da Financiadora de Estudos e Projetos (FINEP). Entre as empresas respondentes, o menor número é de quatro empregados, em duas delas, e a maior possui 200 empregados.

Em relação à adesão ao Programa NAGI, uma das empresas respondentes da pesquisa aderiu em 2012, cinco em 2013, quatro em 2014 e duas no ano de 2015. As motivaçóes apontadas para a inserção no Programa foram: (i) identificar e aproximar linhas de fomento público ou privado para desenvolver inovaçôes, quatro empresas; (ii) implantar um processo de gestão da inovação na empresa, quatro empresas; (iii) aprimorar a eficácia do processo organizacional, duas empresas; e (iv) identificar novas oportunidades de negócios.

De modo geral, percebe-se que a amostra compóe-se de pequenas organizaçóes, tanto industriais como de serviços, porém, estão preocupadas com a questão de inovaçóes, tanto, que a maioria recorreu ao Programa em busca de implementaçáo de processos inovativos.

\subsection{Iniciativas de inovaçáo promovidas nas empresas com o Programa NAGI}

Os resultados das estatísticas descritivas e entropia informacional das iniciativas de inovação promovidas nas empresas com o Programa NAGI são apresentadas na Tabela 1. 
Tabela 1. Iniciativas de inovação promovidas pelo Programa NAGI

\begin{tabular}{|c|c|c|c|c|c|c|}
\hline Iniciativas de inovaçáo promovidas pelo Programa NAGI & Média & Moda & Mín. & Máx. & Entropia & $\begin{array}{l}\text { Peso da } \\
\text { informaçáo }\end{array}$ \\
\hline \multicolumn{7}{|l|}{ Oportunidades de negócios } \\
\hline 1) A empresa ofertou para o mercado um novo bem ou serviço. & 3,33 & 5 & 1 & 5 & 0,940239 & 0,049078 \\
\hline 2) A empresa desenvolveu um novo método de produção. & 2,58 & 4 & 1 & 4 & 0,936441 & 0,052197 \\
\hline 3) A empresa identificou novas oportunidades no mercado. & 3,50 & 5 & 1 & 5 & 0,945943 & 0,044394 \\
\hline $\begin{array}{l}\text { 4) A empresa conquistou uma nova fonte de matéria prima ou de bens semiestru- } \\
\text { turados. }\end{array}$ & 2,50 & 1 & 1 & 5 & 0,930622 & 0,056976 \\
\hline 5) A empresa estabeleceu uma nova estrutura organizacional. & 3,00 & 4 & 1 & 5 & 0,946416 & 0,044006 \\
\hline \multicolumn{7}{|l|}{ Gestão da inovação } \\
\hline $\begin{array}{l}\text { 6) A empresa realiza a gestáo estratégica, acompanhamento da evoluçáo tecnoló- } \\
\text { gica e planejamento de longo prazo. }\end{array}$ & 3,33 & 5 & 1 & 5 & 0,946200 & 0,044183 \\
\hline $\begin{array}{l}\text { 7) A empresa realiza a gestáo da análise e desenvolvimento, incluindo determi- } \\
\text { nação da viabilidade econômica de projetos de desenvolvimento e inovaçáo. }\end{array}$ & 3,33 & 5 & 1 & 5 & 0,954883 & 0,037052 \\
\hline $\begin{array}{l}\text { 8) A empresa realiza a gestáo do processo de desenvolvimento de novos produtos } \\
\text { ou serviços. }\end{array}$ & 3,58 & 4 & 1 & 5 & 0,952887 & 0,038691 \\
\hline $\begin{array}{l}\text { 9) A empresa realiza a gestáo dos fatores que influenciam o sucesso da introduçáo } \\
\text { de inovaçóes tecnológicas no mercado ou na empresa. }\end{array}$ & 3,00 & 4 & 1 & 5 & 0,950214 & 0,040886 \\
\hline $\begin{array}{l}\text { 10) A empresa realiza a gestáo da transferência de tecnologia entre a empresa e } \\
\text { entidades externas. }\end{array}$ & 1,58 & 1 & 1 & 3 & 0,946145 & 0,044228 \\
\hline $\begin{array}{l}\text { 11) A empresa realiza a gestão de aprovisionamentos tecnológicos e escolha de sis- } \\
\text { temas e equipamentos para os processos produtivo, administrativo e de gestáo. }\end{array}$ & 2,42 & 1 & 1 & 5 & 0,924863 & 0,061706 \\
\hline 12) A empresa realiza a gestão de design para engenharia. & 2,67 & 1 & 1 & 5 & 0,935077 & 0,053317 \\
\hline 13) A empresa realiza a gestão da qualidade dos produtos e dos processos. & 3,33 & 5 & 1 & 5 & 0,949619 & 0,041375 \\
\hline 14) A empresa realiza a gestão de recursos humanos de elevada qualificação técnica. & 3,00 & 4 & 1 & 5 & 0,940567 & 0,048809 \\
\hline \multicolumn{7}{|l|}{ Captação de fomento } \\
\hline $\begin{array}{l}\text { 15) A empresa desenvolve projetos que objetivam melhorar um produto, processo, } \\
\text { serviço ou método. }\end{array}$ & 3,67 & 5 & 1 & 5 & 0,951999 & 0,039420 \\
\hline $\begin{array}{l}\text { 16) A empresa desenvolve projetos com o objetivo de captar recursos junto às agên- } \\
\text { cias de fomento. }\end{array}$ & 3,75 & 5 & 1 & 5 & 0,959072 & 0,033612 \\
\hline $\begin{array}{l}\text { 17) A empresa desenvolve projetos com o objetivo de captar fomento para Pesquisa, } \\
\text { Desenvolvimento e Inovação (PD\&I) junto a instituiçóes públicas/ privadas. }\end{array}$ & 3,25 & 5 & 1 & 5 & 0,950818 & 0,040390 \\
\hline $\begin{array}{l}\text { 18) A empresa desenvolve projetos com o objetivo de captar subvenção econômica } \\
\text { junto a instituiçóes públicas. }\end{array}$ & 2,92 & 5 & 1 & 5 & 0,927138 & 0,059837 \\
\hline \multicolumn{7}{|l|}{ Desenvolvimento e inovação } \\
\hline $\begin{array}{l}\text { 19) A empresa identifica os processos necessários para a gestão da PD\&I, assim } \\
\text { como a definiçáo de como estes serão implementados na empresa. }\end{array}$ & 3,33 & 4 & 1 & 5 & 0,957425 & 0,034964 \\
\hline 20) A empresa determina a sequência e interação dos processos de PD\&I. & 3,17 & 5 & 1 & 5 & 0,947544 & 0,043079 \\
\hline $\begin{array}{l}\text { 21) A empresa determina os critérios e métodos necessários para assegurar que a } \\
\text { operaçáo e o controle dos processos sejam eficazes. }\end{array}$ & 3,33 & 4 & 1 & 5 & 0,963386 & 0,030069 \\
\hline $\begin{array}{l}\text { 22) A empresa garante a disponibilidade de recursos e informaçóes para apoiar a } \\
\text { operaçáo e o monitoramento dos processos de PD\&I. }\end{array}$ & 2,75 & 4 & 1 & 4 & 0,958934 & 0,033725 \\
\hline $\begin{array}{l}\text { 23) A empresa realiza a implementação de açóes necessárias para atingir os resulta- } \\
\text { dos planejados e a melhoria contínua dos processos de PD\&I. }\end{array}$ & 3,08 & 4 & 1 & 5 & 0,965901 & 0,028004 \\
\hline
\end{tabular}

Fonte: Dados da pesquisa. 
Observa-se na Tabela 1 o escopo do programa NAGI quanto às iniciativas promovidas pelas empresas. No que tange às oportunidades de negócios, a que foi praticada com maior frequência é a oferta para o mercado de um novo bem ou serviço. Por sua vez, a oportunidade que se mostra ausente do escopo empresarial dos indivíduos pesquisados é identificação de nova fonte de matéria prima ou bens semiestruturados. Realizando uma analogia com o que é preconizado por Schumpeter (1988), no que tange à capacidade de inovação das empresas, esta compreende a combinação de materiais e forças que surgem descontinuamente e refere-se à introdução de um novo bem ou serviço para o mercado.

O processo inovativo pode contribuir para o desenvolvimento e implementação de práticas que podem ser convergidas em valores sociais e econômicos (Martins, Alves \& Plonski, 2013). Dentro desse escopo, as assertivas que foram apontadas com maior frequência pelas empresas investigadas ocorreram dentro de três perspectivas principais: a primeira consiste em realizar a gestáo estratégica, o acompanhamento da tecnologia e o planejamento de longo prazo; a segunda está em realizar a gestão da análise e desenvolvimento, incluindo determinação da viabilidade econômica de projetos de desenvolvimento e inovação; e a terceira refere-se a realizar a gestáo da qualidade dos produtos e dos processos.

No entanto, ainda no que se refere à implementação da inovaçáo como iniciativa promovida pelo Programa NAGI, é válido destacar que as empresas pesquisadas têm encontrado dificuldades em: i) gerir a transferência de tecnologia entre a empresa e entidades externas; ii) realizar a gestão de aprovisionamentos tecnológicos e escolha de sistemas e equipamentos para os processos produtivo, administrativo e de gestâo; e iii) realizar a gestão de design para engenharia, sendo que a indicação máxima dentro desse tripé verificada na pesquisa é três, ou seja, um item que carece de atenção frente as demais iniciativas propostas pelo Programa, no sentido de mitigar os riscos que cercam tal assertiva.

Outro aspecto observado nas iniciativas promovidas pelo Programa NAGI nas empresas é quanto à captação de fomento, pois o desenvolvimento da inovaçáo ao longo do tempo nas empresas tende a ser fundamental. Entretanto, o processo inovativo é oneroso, logo, a captação de fomento favorece o desenvolvimento desse processo. Assim, todas as empresas participantes desta pesquisa buscaram identificar linhas de fomento público ou privado para o desenvolvimento de inovaçóes, merecendo destaque a captação de recursos junto à agência de fomento, que teve maior frequência de respostas junto aos pesquisados.

Desenvolver o processo inovador na empresa é uma tarefa que demanda a concepção de estratégias competitivas (Tavares, Aquino \& Paiva, 2014). Dessa forma, identificar os processos necessários para a gestão da Pesquisa, Desenvolvimento e Inovação (PD\&I) é visto com prioridade pelas organizaçóes pesquisadas. Porém, chama atenção o aspecto de disponibilidade de recursos e informaçóes para apoiar a operação e o monitoramento dos processos de PD\&I apresentar média inferior às demais do grupo, o que corrobora para o argumento preconizado pela literatura, quanto ao custo do processo inovativo.

Ao comparar os objetivos do Programa, que encontram-se disponíveis no site do mesmo, com os resultados apresentados, observa-se que o objetivo de identificação de oportunidades de negócios vem sendo parcialmente alcançado. No entanto, existe fragilidade com o objetivo de implantaçáo e desenvolvimento do processo de gestão da inovação na organização, 
cujos resultados estão alinhados com o que a literatura enfatiza. Martins, Alves e Plonski (2013, p. 01) afirmam que «toda vez que se trata do tema, seja a inovação de produto, de processo ou mesmo de uma prática gerencial, depara-se com uma dificuldade de desenvolvimento e implementação». Tais resultados podem ainda estar relacionados com o fato de que a adesão ao Programa ocorreu recentemente na maioria das empresas.

Além da estatística descritiva, utilizou-se a entropia informacional para análise dos resultados. $\mathrm{O}$ valor da entropia indica a quantidade de informação, sendo que maior entropia indica menos informação e menor entropia mais informação (Beuren, Cunha, Theiss \& Cordeiro, 2013). Zeleny (1982) explica que a entropia informacional não se baseia na média e sim em um ponto de referência selecionado pelo pesquisador, em que se analisam as respostas que estáo mais distantes do ponto de referência escolhido, ou seja, menos esperadas pelo pesquisador, o que acaba por avaliar a quantidade de informaçáo existente em uma pergunta ou um conjunto de perguntas. Com a técnica da entropia informacional é possível avaliar a dispersão das respostas, enfatizando aquelas com maior variação na escala proposta. Para tanto, analisa-se a entropia e(di) e o peso da informaçáo $\left(\lambda_{i}\right)$. Desse modo, quanto maior a entropia - e(di ), menor o peso informacional $\left(\lambda_{i}\right)$ e menor a dispersáo dos resultados; e, quanto menor a entropia, maior o peso informacional e maior a variabilidade nas respostas.

Observa-se na Tabela 1, que as entropias apresentam valores distintos e de certo modo distantes, o que indica dispersão nas respostas dentro das categorias analisadas. Analisando o grupo de questôes, nota-se que a questão 23, «a empresa realiza a implementação de açóes necessárias para atingir os resultados planejados e a melhoria contínua dos processos de PD\&I», foi a que obteve maior entropia, com e (di) de 0,965901, demonstrando que essas questóes apresentaram a menor informação entre as questóes do grupo. Em outras palavras, nessa questão houve menor dispersão nas respostas. Em relação ao peso, nota-se que a questão 11 , «A empresa realiza a gestão de aprovisionamentos tecnológicos e escolha de sistemas e equipamentos para os processos produtivo, administrativo e de gestão» e a questáo 12 "A empresa desenvolve projetos com o objetivo de captar subvenção econômica junto a instituições públicas», apresentaram o maior peso $\left(\lambda_{i}\right)$, demonstrando que essas questóes foram as que apresentaram maior diversidade de opiniōes entre os respondentes. Estas questôes estão relacionadas à categoria gestão da inovação, itens que apresentaram maior efeito surpresa em suas respostas, o que destoa das motivaçóes apontadas pelas empresas para adesão ao Programa. Assim, considera-se pertinente analisar tais situaçóes, visto que os respondentes possuem opiniōes bastante distintas sobre o tema.

De modo geral, ao analisar a entropia e, consequentemente, o peso da informação, observa-se que as respostas com menores dispersóes estão relacionadas aos aspectos de desenvolvimento de projetos, seja com o intuito de captar recursos, melhorar e desenvolver produtos ou até mesmo identificar, definir e mapear processos e açóes para atingir os resultados planejados. Por sua vez, as questóes com maiores dispersóes estão relacionadas ao processo de gestão, desenvolvimento e inovação de produtos e processos, ou seja, as empresas encontram-se ainda em fase de planejamento do processo inovativo e apenas algumas delas estão em execução, o que requer uma análise minuciosa por parte dos gestores destas organizaçóes e do próprio projeto analisado. 


\subsection{Práticas de controle gerencial antes e após a adoçáo do Programa NAGI}

$\mathrm{Na}$ Tabela 2, evidenciam-se os reflexos da adoção do Programa NAGI nas práticas de controle gerencial das empresas investigadas. Neste bloco, as empresas indicavam o grau de utilização das práticas de controle gerencial, numa escala de 0 a 4 , sendo $0=$ náo utiliza e $4=$ utiliza muito.
Verifica-se na Tabela 2, que algumas práticas gerenciais sofreram alterações no grau de utilização após a adoção do Programa NAGI. Ao observar a moda, nota-se que houve variaçóes de maior número de respostas nos instrumentos de controle de estoques, controle de custos e despesas, controle de resultados, custeio variável, custeio padrão, planejamento tributário, orçamento, avaliação de desempenho, simulaçóes

Tabela 2. Reflexos da adoçáo do Programa NAGI nas práticas de controle gerencial

\begin{tabular}{|c|c|c|c|c|c|c|c|c|}
\hline \multirow[b]{2}{*}{ Práticas gerenciais } & \multicolumn{4}{|c|}{ Uso antes da adoção do Programa NAGI } & \multicolumn{4}{|c|}{ Uso após a adoção do Programa NAGI } \\
\hline & Média & Moda & Entropia & $\begin{array}{c}\text { Peso da } \\
\text { informaçáo }\end{array}$ & Média & Moda & Entropia & $\begin{array}{c}\text { Peso da } \\
\text { informaçáo }\end{array}$ \\
\hline \multicolumn{9}{|l|}{ Controles operacionais } \\
\hline Controle de caixa & 2,75 & 4 & 0,96437 & 0,045639 & 3,33 & 4 & 0,989177 & 0,015456 \\
\hline Controle de contas a pagar & 3,33 & 4 & 0,982498 & 0,022419 & 3,50 & 4 & 0,991212 & 0,012549 \\
\hline Controle de contas a receber & 3,25 & 4 & 0,980519 & 0,024954 & 3,42 & 4 & 0,989183 & 0,015447 \\
\hline Controle de estoques & 1,92 & 2 & 0,970327 & 0,03801 & 2,67 & 4 & 0,973205 & 0,038265 \\
\hline Controle de vendas & 2,67 & 3 & 0,962204 & 0,048415 & 2,83 & 3 & 0,975636 & 0,034794 \\
\hline Controle de custos e despesas & 3,08 & 3 & 0,992909 & 0,009083 & 3,08 & 4 & 0,988043 & 0,017075 \\
\hline Controle de resultados & 2,58 & 3 & 0,985028 & 0,019178 & 2,83 & 4 & 0,973425 & 0,037951 \\
\hline Demonstraçôes contábeis & 2,75 & 4 & 0,972088 & 0,035753 & 3,25 & 4 & 0,989323 & 0,015248 \\
\hline \multicolumn{9}{|l|}{ Métodos de custeio } \\
\hline Custeio por absorção & 1,33 & 2 & 0,944735 & 0,070791 & 2,00 & 2 & 0,950214 & 0,071098 \\
\hline Custeio variável & 1,67 & 0 & 0,942528 & 0,073618 & 2,08 & 3 & 0,95007 & 0,071304 \\
\hline Custeio padrão & 1,83 & 2 & 0,954514 & 0,058264 & 1,92 & 0 & 0,936856 & 0,090175 \\
\hline Custeio baseado em atividades (ABC) & 1,08 & 0 & 0,949264 & 0,06499 & 1,17 & 0 & 0,930185 & 0,099701 \\
\hline Custeio meta & 1,00 & 0 & 0,94166 & 0,07473 & 1,25 & 0 & 0,922191 & 0,111117 \\
\hline \multicolumn{9}{|c|}{ Outros instrumentos/Práticas gerenciais } \\
\hline Planejamento estratégico & 2,42 & 4 & 0,969946 & 0,038497 & 3,25 & 4 & 0,992004 & 0,011419 \\
\hline Planejamento tributário & 2,17 & 2 & 0,951142 & 0,062584 & 2,33 & 3 & 0,957425 & 0,0608 \\
\hline Ponto de equilíbrio & 2,25 & 4 & 0,954324 & 0,058508 & 2,83 & 4 & 0,973425 & 0,037951 \\
\hline Orçamento & 2,00 & 3 & 0,940567 & 0,076131 & 2,42 & 4 & 0,947189 & 0,075419 \\
\hline Avaliação de desempenho & 1,58 & 2 & 0,948776 & 0,065615 & 2,42 & 3 & 0,953004 & 0,067114 \\
\hline Simulações & 1,92 & 2 & 0,963514 & 0,046736 & 2,42 & 4 & 0,958995 & 0,058558 \\
\hline Margem de contribuição & 1,75 & 3 & 0,948409 & 0,066085 & 2,42 & 4 & 0,958995 & 0,058558 \\
\hline
\end{tabular}

Fonte: Dados da pesquisa. 
e margem de contribuição. Quanto mais próximo de 4, maior é o grau de uso das práticas gerenciais por parte das empresas. Portanto, com exceção do custeio padrão, as demais práticas mencionadas que sofreram alteraçóes passaram a ter maior uso por um número maior de empresas.

Em relação aos métodos de custeio, verifica-se que o custeio variável passou a ser utilizado pelas organizações após a adoção do Programa NAGI e o custeio padrão foi abandonado por algumas empresas. Nota-se ainda que o custeio por atividades não é utilizado nestas empresas. Tal fato pode ser atribuído ao porte das empresas investigadas. Controles operacionais foi a categoria mais utilizada pela amostra antes da adoção, e, a partir da adesão ao Programa, os mesmos continuam sendo utilizados, porém, em intensidade superior, sendo que o reflexo maior foi nos controles de estoques.

A categoria outros instrumentos/práticas gerenciais foi a que mais apresentou alteraçóes a partir da adesão ao Programa. Tal categoria está relacionada aos aspectos de planejamento, controle, execução e avaliação. As empresas passaram a utilizar com maior intensidade todos os artefatos investigados, especificamente houve aumento em termos de média na avaliação de desempenho, planejamento estratégico, margem de contribuição, simulações e orçamento. Os níveis de mudança nas práticas de controle gerencial identificados coadunam com os resultados da pesquisa de Sulaiman e Mitchel (2005), em que as práticas de planejamento, controle e custeio foram as que mais apresentaram mudanças com a introdução da inovação nas organizaçóes. Esse alinhamento estende-se às pesquisas nacionais, como a de Frezatti et al. (2015), de que as mudanças mais significativas ocorreram em planejamento estratégico e orçamento, cujas práticas de controle gerencial contribuem para a implementação e controle dos processos de inovação.

Ao analisar a entropia e o peso da questáo, nota-se que antes da adoçáo do Programa, as práticas de controle de custos e despesas, controle de resultados e controle de contas a pagar apresentavam a maior entropia, ou seja, se constituíam nas práticas com menor dispersão de respostas. A partir da adoção no Programa NAGI, as práticas gerenciais com maior entropia e, consequentemente, menor peso da questáo passaram a ser o planejamento estratégico, controles de contas a pagar e demonstraçóes contábeis. Isso indica que as empresas passaram a fazer maior uso das demonstraçóes contábeis no processo de tomada de decisóes e, principalmente, passaram a utilizar com maior intensidade, de forma homogênea, o planejamento estratégico. Tal fato era esperado, uma vez que está relacionado com a proposta do Programa e com as iniciativas de inovaçáo identificadas na Tabela 1.

Em relação às práticas que apresentaram maior efeito surpresa em suas respostas, apresentando maior quantidade de informação, ou seja, maiores dispersóes, estão o orçamento, custeio meta e custeio variável, antes da adesão ao Programa. A partir da adoção do Programa, as práticas com maiores dispersóes, ou seja, menor entropia, passaram a ser o custeio meta, custeio $\mathrm{ABC}$ e custeio padrão, o que indica mudanças significativas em termos de métodos de custeio.

Para melhor visualização, o Gráfico 1 evidencia o grau de uso de algumas práticas gerenciais antes e após a adoção do Programa NAGI, calculados por meio da entropia informacional. Para o cálculo da entropia, a escala de $0=$ não utiliza a $4=$ utiliza muito foi transformada numa escala de 1 a 5 , sendo $1=$ não utiliza e $5=$ utiliza muito. 
Gráfico 1. Entropia informacional de práticas gerenciais antes e após a adoção do NAGI
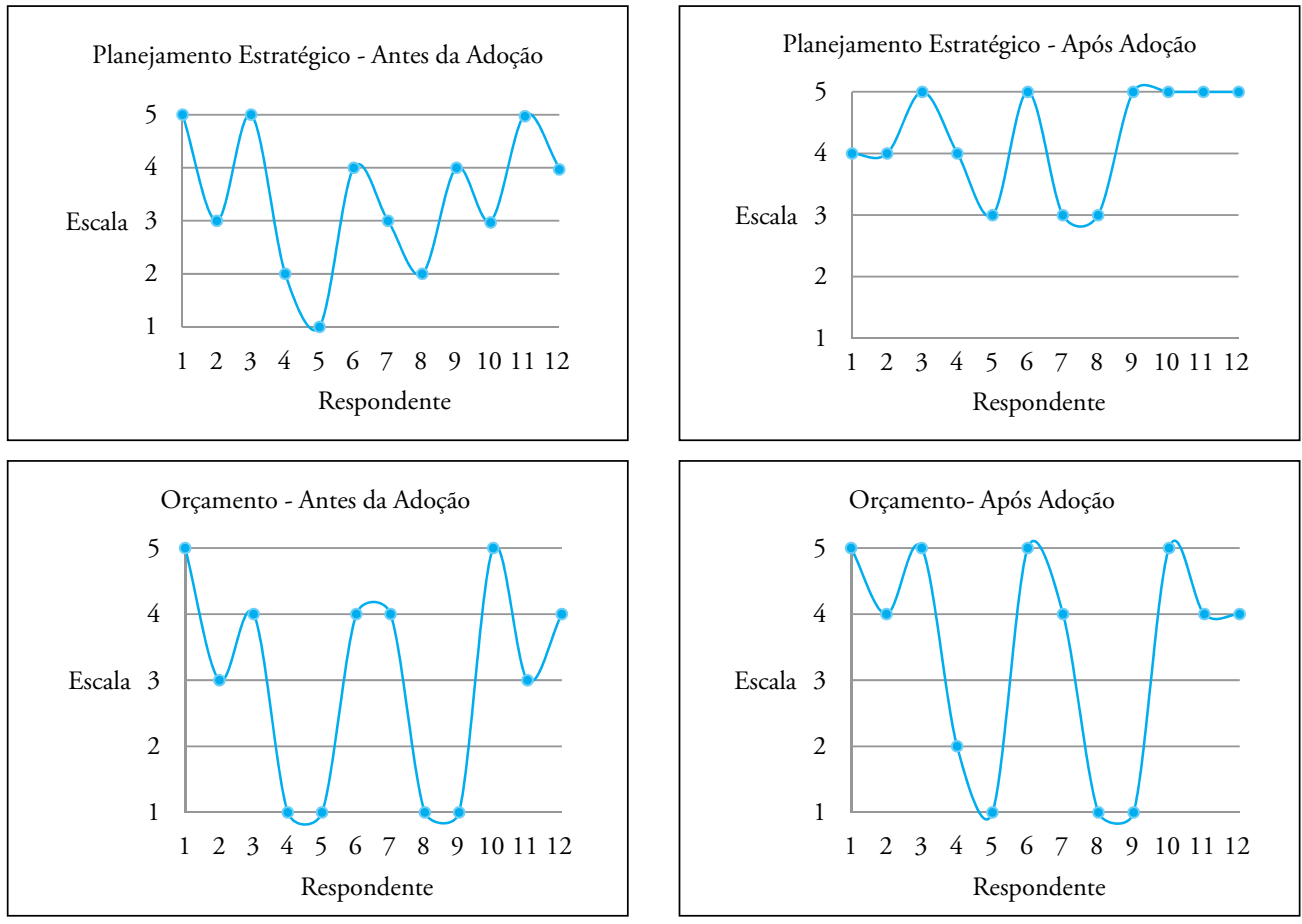

Avaliaçáo de Desempenho - Antes da Adoção

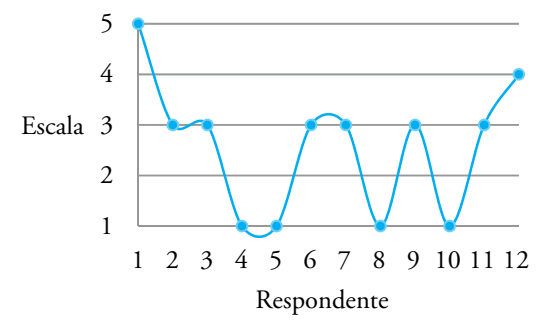

Demonstraçōes Contábeis - Antes da Adoção
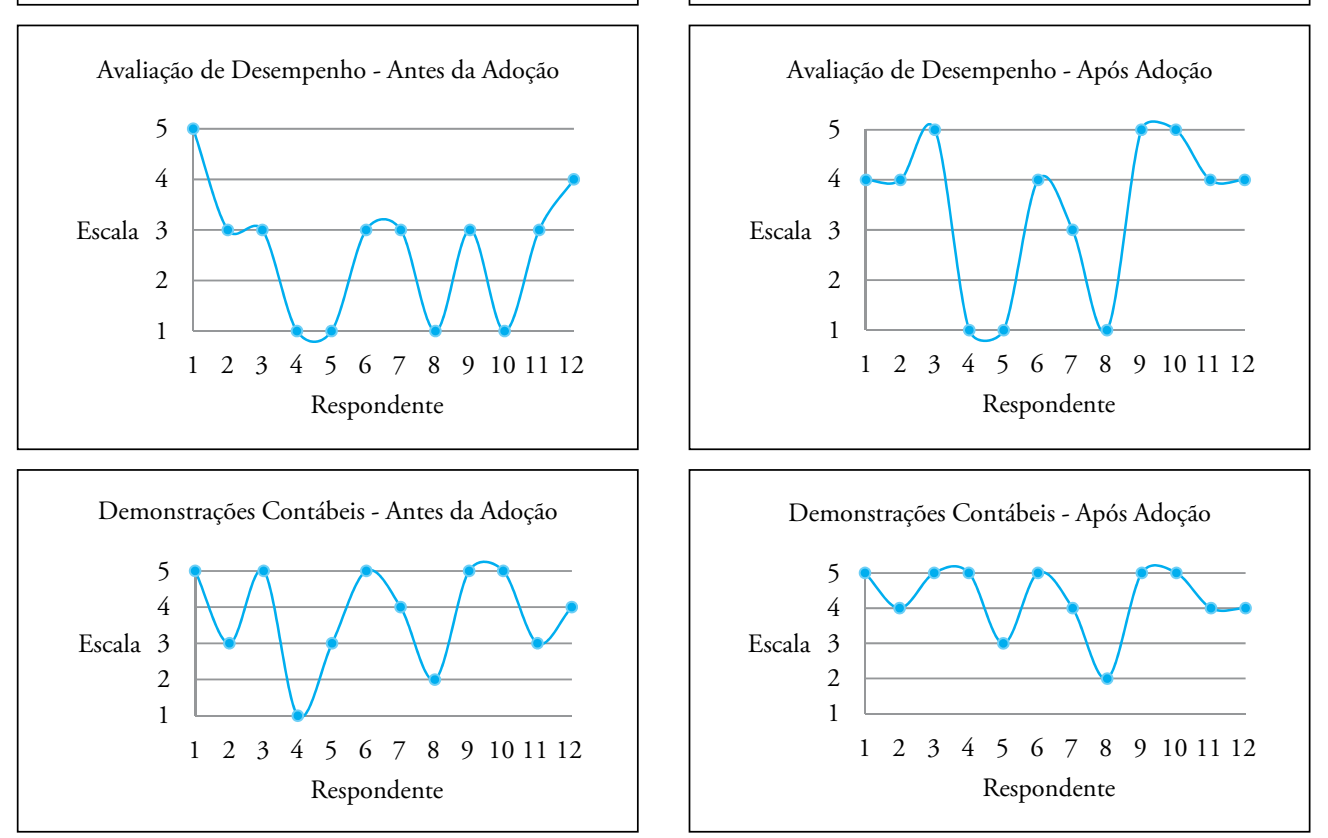

Fonte: Dados da pesquisa. 
Depreende-se do Gráfico 1, que as práticas gerenciais sofreram alterações em algumas empresas com a adoção do Programa NAGI. O planejamento estratégico, o orçamento, a avaliaçáo de desempenho e as demonstraçóes contábeis passaram a ser muito utilizados por um número maior de empresas. Estes resultados coadunam com as tipologias de mudanças em práticas de controles gerenciais evidenciadas na pesquisa de Sulaiman e Mitchell (2005).

$\mathrm{Na}$ Tabela 3, apresenta-se sobre as mudanças ocorridas nas práticas gerenciais, conforme a percepção dos respondentes, em consonância com a tipologia de Sulaiman e Mitchell (2005).

Nota-se na Tabela 3, que todas as tipologias de mudanças em práticas de controle gerencial propostas por Sulaiman e Mitchell (2005) estão presentes na adoção do Programa NAGI pelas empresas investigadas. As empresas introduziram, modificaram, alteraram técnicas gerenciais visando às iniciativas de inovação. Ao verificar as escalas de grau de concordância (concordo totalmente e concordo parcialmente), percebe-se que a tipologia adição e reposição tiveram maior número de empresas. Desta forma, empresas passaram a utilizar novos instrumentos gerenciais, por exemplo, avaliação de desempenho, planejamento estratégico, além de introduzir técnicas complementares às existentes, como é o caso do custeio variável, que complementa o custeio por absorção. Em algumas empresas houve modificaçóes de relatórios, tal observação converge com o aumento do uso das demonstrações contábeis, conforme já destacado na Tabela 2 e Figura 1. Ocorreu ainda, mesmo que de forma tímida, modificação operacional, podendo se fazer uma analogia da substituição do custeio padrão pelo custeio variável, ambos métodos de custeio para fins gerenciais.

Ressalta-se ainda que duas empresas mencionaram a categoria estabilidade, ou seja, nenhuma modificação foi realizada com a adoção do Programa NAGI, o que requer uma investigaçáo pormenorizada nestas organizaçóes. De modo geral, a adoção do Programa NAGI proporcionou a introdução e modificação de novas práticas gerenciais nas empresas investigadas, visando o aperfeiçoamento dos produtos e processos organizacionais.

\section{Tabela 3. Tipologia de mudanças em práticas de controle gerencial}

\begin{tabular}{|c|c|c|c|c|c|c|}
\hline Tipologia de mudanças em práticas de controle gerencial & DT & DP & I & $\mathrm{CP}$ & $\mathrm{CT}$ & Média \\
\hline $\begin{array}{l}\text { Adição - após a adoção do Programa NAGI a empresa introduziu novas técnicas de controle geren- } \\
\text { cial, ainda não existentes na empresa. }\end{array}$ & 3 & 2 & 2 & 3 & 2 & 2,92 \\
\hline $\begin{array}{l}\text { Reposição - após a adoçáo do Programa NAGI a empresa introduziu novas técnicas, porém, com- } \\
\text { plementares às técnicas atuais. }\end{array}$ & 5 & 1 & 1 & 4 & 1 & 2,92 \\
\hline $\begin{array}{l}\text { Modificação do relatório - após a adoção do Programa NAGI a empresa realizou mudanças na forma } \\
\text { de apresentação das informaçóes, quanto à frequência, tipo de apresentação, etc. }\end{array}$ & 5 & 2 & 2 & 2 & 1 & 2,67 \\
\hline $\begin{array}{l}\text { Modificaçáo operacional - após a adoçáo do Programa NAGI, a empresa realizou mudanças no } \\
\text { critério de uma técnica já existente, por exemplo, custo médio em vez de PEPS. }\end{array}$ & 5 & 3 & 1 & 2 & 1 & 2,58 \\
\hline Estabilidade - nenhuma modificação foi realizada nesse período após a adoção do Programa NAGI & 4 & 4 & 2 & 1 & 1 & 2,25 \\
\hline $\begin{array}{l}\text { Redução - após a adoção do Programa NAGI a empresa abandonou técnica(s) de controle gerencial, } \\
\text { sem reposição por outra. }\end{array}$ & 8 & 1 & 1 & 2 & 0 & 1,75 \\
\hline
\end{tabular}

Legenda: DT=Discordo Totalmente; DP=Discordo Parcialmente; I=Indiferente; CP=Concordo Parcialmente; CT=Concordo Totalmente. Fonte: Dados da pesquisa. 


\section{Consideraçóes finais}

O estudo objetivou identificar os reflexos da adoção do Programa de Núcleos de Apoio à Gestão da Inovação (NAGI) nas práticas de controle gerencial em empresas. Os resultados evidenciaram que as iniciativas de inovação promovidas pelo Programa NAGI e presentes de forma mais homogênea nas organizaçóes estão relacionadas à identificação de processos necessários à gestão de Pesquisa, Desenvolvimento \& Inovação; à garantia de disponibilidade de recursos e informaçôes para apoiar a operação e o monitoramento destes processos; o desenvolvimento de projetos com o objetivo de captar recursos junto à agência de fomento; e à implementação de açóes para atingir os resultados planejados e a melhoria contínua dos processos de PD\&I.

Entretanto, há algumas iniciativas que estão dispersas entre as organizaçóes, ou seja, em que se constata maior variabilidade, tais como: o desenvolvimento de um novo método de produção, a oferta para o mercado de um novo bem ou serviço, o desenvolvimento de projetos para captar subvenção junto a instituiçôes públicas, a escolha de sistemas e equipamentos para os processos produtivo, administrativo e de gestão. Tais resultados apresentam pequenos indícios de que as empresas investigadas ainda estão na fase de codificação no que concerne ao processo de inovação. As atividades melhor estruturadas e que contemplam todas as organizaçóes são de mapeamento e planejamento de ações, e a elaboração de projetos.

Contudo, há indícios de que ainda não ocorreram em todas as empresas inovaçóes na oferta de bens e serviços e há dificuldades destas em captar recursos de órgãos públicos. Isso demonstra que as motivações que levaram as empresas a ingressarem no Programa estão sendo parcialmente alcançadas. Os motivos apontados foram: identificação de novas oportunidades de

negócios, identificação e aproximação de linhas de fomento público ou privado para desenvolver inovaçóes, aprimoramento da eficácia do processo organizacional e implantação de um processo de gestáo da inovação na empresa. Entretanto, os resultados merecem ressalvas, como: as empresas ingressaram no Programa recentemente; as motivaçôes foram distintas; o processo de inovaçáo, especificamente mudanças de processo produtivo, modificaçóes na oferta de novos bens e serviços, é oneroso e demanda tempo; e a pequena amostra de pequenas empresas, sendo a maioria tributada pelo Simples Nacional.

Estas modificaçóes graduais foram constatadas no que concerne à utilização das práticas gerenciais. Antes da implementação do projeto, as empresas utilizavam com maior ênfase os controles operacionais, sendo que os métodos de custeio e outros instrumentos, como avaliação de desempenho, planejamento estratégico, orçamento, eram utilizados com menor frequência. A partir da implementação do Programa NAGI, ocorreram mudanças no controle e gerenciamento de estoques, as empresas passaram a utilizar com mais intensidade e de forma pouco mais homogênea o custeio variável, além da utilização do ponto de equilíbrio e margem de contribuiçáo para a tomada de decisóes. Constatou-se ainda que a utilização das demonstrações contábeis foi ampliada e ocorreu de forma menos dispersa.

Com a adoção do Programa NAGI, o planejamento estratégico tornou-se a prática que apresentou menor dispersão entre as empresas investigadas, o que indica sua institucionalização pela adoção do Programa. Os níveis de mudança nas práticas de controle gerencial coadunam com os resultados da pesquisa de Sulaiman e Mitchel (2005), em que as práticas de planejamento, controle e custeio foram as que mais apresentaram mudanças com a introdução da inovação nas empresas. Desse modo, as empresas introduziram, modificaram, 
alteraram técnicas gerenciais visando às iniciativas de inovaçóes propostas.

Os resultados da pesquisa requerem parcimônia nas inferências em função das limitaçóes importas ao estudo, em especial a pequena quantidade de respondentes, o que inviabiliza avançar nas análises e generalizar as conclusóes. Entretanto, o estudo oferece insights para investigaçóes futuras. Recomenda-se realizar um estudo longitudinal em empresas que aderiram ao Programa, para compreender e analisar as iniciativas de inovaçóes promovidas ao longo do tempo e as modificaçóes ocorridas nas práticas de controle gerencial. Pode-se ainda investigar as mudanças de controle gerencial com outras iniciativas governamentais que possuem o propósito de fomentar a inovação. Além disso, investigar a relação de tipos de inovação com determinados instrumentos gerenciais.

\section{Referências}

Bisbe, J. \& Otley, D. (2004). The effects of the interactive use of management control systems on product innovation. Accounting, Organizations and Society, 29(8), 709-737. https://doi.org/10.1016/j.aos.2003.10.010

Beuren, I. M., Cunha, P. R., Theiss, V. \& Cordeiro, A. (2010). Percepção dos discentes da disciplina de contabilidade introdutória: uma análise por meio da entropia informacional em diferentes cursos de graduação. $R e-$ vista de Contabilidade e Organizaçóes, 7(19), 70-85. https://doi.org/10.11606/rco.v7i19.62890

Camisón, C. \& Villar-López, A. (2014). Organizational innovation as an enabler of technological innovation capabilities and firm performance. Journal of Business Research, 67(1), 2891-2902. https://doi. org/10.1016/j.jbusres.2012.06.004

Couto, F. S. \& Turetta, A. L. (2013). NAGI e MEI: iniciativas para alavancar a inovação e a competitividade da indústria Paranaense. Caderno INTEC 3 - Desenvolvimento Empresarial, Tecnologia \& Inovaçâo. Curitiba: TECPAR.
Davila, T. (2000). An empirical study on the drivers of management control systems' design in new product development. Accounting, Organizations and Society, 25(4), 383-409. https://doi.org/10.1016/ S0361-3682(99)00034-3

Davila, T., Epstein, M. J. \& Shelton, R. (2007). As regras da inovação. Porto Alegre: Bookman.

Dias Filho, J. M. \& Nakagawa, M. (2001). Análise do processo da comunicação contábil: uma contribuição para a soluçáo de problemas semânticos, utilizando conceitos da teoria da comunicação. Revista Contabilidade \& Finanças, 12(26), 42-57.

Drucker, P. (1999). Inovação e espirito empreendedor: prática e princípios. São Paulo: Pioneira.

Dunk, A. S. (2011). Product innovation, budgetary control, and the financial performance of firms. The British Accounting Review, 43(2), 102-111. https:// doi.org/10.1016/j.bar.2011.02.004

Frezatti, F., Bido, D. S., Cruz, A. P. C. \& Machado, M. J. C. (2015). A estrutura de artefatos de controle gerencial no processo de inovação: existe associação com o perfil estratégico? Brazilian Business Review, 12(1), 129-156.

Garcia, C. (2014). Lei do Bem: como alavancar a inovação com a utilização de incentivos fiscais. São Paulo: Ed. Pillares.

Li, Y. (2014). Environmental innovation practices and performance: moderating effect of resource commitment. Journal of Cleaner Production, 66(5), 450-458. https:// doi.org/10.1016/j.jclepro.2013.11.044

Lima, A. N. (2007) Um estudo sobre a importância do uso das ferramentas de controle gerencial nas micro, pequenas e médias empresas industriais no município de São Caetano do Sul. Dissertação de Mestrado, Universidade Metodista de São Paulo, São Bernardo do Campo, SP, Brasil.

Lima, A. N. \& Imoniana, J. O. (2008). Um estudo sobre a importância do uso das ferramentas de controle gerencial nas micro, pequenas e médias empresas industriais no município de São Caetano do Sul. Revista da Micro e Pequena Empresa, 2(3), 28-48. 
Lopes, I. F. \& Beuren, I. M. (2014). Evidenciaçáo da Inovação no Relatório da Administraçáo: uma análise na perspectiva da Lei do Bem (Lei No. 11.196/2005). In: Congresso USP de Iniciação Científica em Contabilidade, 11., 2014, São Paulo. Anais... São Paulo: FEA/USP.

Loures, M. \& Bicalho, T. (2014). Contextualização da política e inovação no Brasil. In C. Garcia (org.). Como alavancar a inovaçâo com a utilização dos incentivos fiscais. (pp. 17-26). Sáo Paulo: Pillares.

Martins, P. S., Alves, L. H. D. \& Plonski, G. A. (2013). Gestão da inovação: uma análise da utilização de ferramentas pelas empresas. In: Congreso LatinoIberoamericana de Gestión Tecnológica, 15, 2013, Porto. Anais... Porto: ALTEC.

Mat, T., Smith, M. \& Djajadikerta, H. (2010). Determinants of management accounting change in Malaysian manufacturing companies. Asian Journal of Accounting and Governance, 1(1), 79-104. https://doi. org/10.17576/ajag-2010-1-6547

Nisiyama, E. K. \& Oyadomari, J. C. T. (2012). Sistemas de controle gerencial e o processo de inovação. Revista de Administração e Inovação, 9(1), 106-125. https://doi. org/10.5773/rai.v1i1.634

Núcleo de Apoio à Gestão da Inovação (NAGI). Disponível em: <http://nagipr.org.br/>. Acesso em: 01 maio 2015.

Oyadomari, J. C. T., Aguiar, A. B., Chen, Y-T. \& DultraDe-Lima, R. G. (2013a). Inovação de práticas de controle gerencial e fontes de informação. Revista de Contabilidade e Organizaçóes, 7(19), 16-26. https:// doi.org/10.11606/rco.v7i19.55424

Oyadomari, J. C. T., Mendonça Neto, O. R. \& Cardoso, R. L. (2013b). Fatores indutores de inovação e manutenção de práticas de controle gerencial: um estudo exploratório. Revista Universo Contábil, 9(2), 125-141. https:// doi.org/10.4270/ruc.2013216

Oyadomari, J. C. T., Cardoso, R. L., Mendonça Neto, O. R. \& Aguiar, A. B. (2013c). Criação de conhecimento em práticas de controle gerencial: análise dos estudos internacionais. Advances in Scientific and Applied Accounting, 6(1), 4-30. https://doi.org/10.14392/ ASAA/2013060101
Panucci Filho, L. \& Almeida, L. B. (2011). A contabilidade gerencial no crescimento das organizaçóes: um estudo nas indústrias de confecçóes. Revista Iberoamericana de Contabilidad de Gestión, 9(18), 1-17.

Schumpeter, J. A. (1988). Teoria do desenvolvimento econômico: uma investigação sobre lucros, capital, credito, juro e o ciclo econômico. São Paulo: Abril Cultural.

Serviço Nacional de Aprendizagem Industrial do Paraná (2014). Programa NAGI-PR Mobilização Empresarial pela Inovação. Curitiba, SENAI.

Simons, R. (1990). The role of management control systems in creating competitive advantage: new perspectives. Accounting, Organizations \& Society, 15(1/2), 17-143. https://doi.org/10.1016/0361-3682(90)90018-p

Soutes, D. O. (2006). Uma investigação do uso de artefatos de contabilidade gerencial por empresas brasileira. Dissertação de Mestrado, Universidade de São Paulo, SP, Brasil. https:// doi.org/10.11606/d.12.2006.tde-12122006-102212

Sulaiman, S. \& Mitchell, F. (2005). Utilising a typology of management accounting change: an empirical analysis. Management Accounting Research, 16(4), 422-437. https://doi.org/10.1016/j.mar.2005.03.004

Tavares, L., Aquino, L. \& Paiva, R. (2014). Estruturação de projetos de PD\&I. In C. Garcia (org.). Lei do Bem: como alavancar a inovaçâo com a utilização de incentivos fiscais. São Paulo: Ed. Pillares.

Tsai, K.-H. (2004). The impact of technological capability on firm performance in Taiwan's electronics industry. The Journal of High Technology Management Research, 15(2), 183-195. https://doi.org/10.1016/j. hitech.2004.03.002

Zeleny, M. (1982). Multiple criteria decision making. New York: McGraw-Hill.

Fecha de recepción: 21 de setiembre del 2016 Fecha de aceptación: 20 de octubre del 2016 Correspondencia: iagoipo@hotmail.com vanderleidossantos09@gmail.com ilse.beuren@gmail.com 